\title{
Exigência de Fósforo Disponível para Frangos de Corte Machos e Fêmeas de 1 a 21 Dias de Idade ${ }^{1}$
}

\section{Richard Cesar Runho², Paulo Cezar Gomes ${ }^{3}$, Horacio Santiago Rostagno ${ }^{3}$, Luiz Fernando Teixeira Albino ${ }^{3}$, Paulo Sávio Lopes ${ }^{3}$, Paulo César Pozza ${ }^{4}$}

\begin{abstract}
RESUMO - Foram utilizados 960 pintos, metade machos e metade fêmeas, no período de 1 a 21 dias idade, com peso inicial médio de 42,5 e 42,1g, respectivamente. O delineamento experimental utilizado foi em blocos casualizados, com seis tratamentos, dois sexos, quatro repetições por sexo e vinte aves por unidade experimental. Os tratamentos consistiram de uma dieta basal deficiente em fósforo $(0,150 \%)$, suplementada com fósforo disponível, provenientes do fosfato bicálcico $(0,0 ; 0,10 ; 0,20 ; 0,30 ; 0,40 ;$ e $0,50 \%)$. As variáveis avaliadas foram ganho de peso (GP), consumo de ração (CR), conversão alimentar (CA), resistência dos ossos à quebra (ROQ), cinzas (CO) e fósforo no osso (PO). As exigências em fósforo disponível foram estimadas por intermédio dos modelos de regressão polinomial e LRP. As suplementações com fósforo disponível influenciaram o GP, CR, CA, ROQ, CO e PO, tanto para os machos como para as fêmeas. As estimativas de exigências de P-disp variaram de 0,259 (0,085\%/Mcal de EM) a 0,559\% (0,184\%/Mcal de EM), para os machos, e de $0,307 \%(0,092 \% / \mathrm{Mcal}$ de EM) a 0,575\% (0,190\%/Mcal de EM) para as fêmeas. Entretanto, considerando as respostas biológicas, para as variáveis de desempenho e características ósseas, pode-se sugerir que a exigência de fósforo disponível, para frangos de corte machos e fêmeas, de 1 a 21 dias de idade, é de 0,45 ou 0,148\% de Pdisp/Mcal de EM.
\end{abstract}

Palavras-chave: exigência de fósforo disponível, frangos, fase inicial

\section{Available Phosphorus Requirement of Male and Female Broilers from 1 to 21 Days of Age}

\begin{abstract}
Ninety and sixty Hubbard one-day-old broilers chicks, half male and half female, were used at the initial phase, from 1 to 21 days of age, with initial weight of 42.5 and $42.1 \mathrm{~g}$, respectively. The chicks were allotted to a randomized block design, with six treatments, two sexes, four replicates per sex and twenty animals per experimental unity. The treatments consisted on deficient basal diet in available phosphorus (.15\%), supplemented with available phosphorus from dicalcium phosphate $(0,0.10,0.20,0.30,0.40$, and $0.50 \%$ ). The weight gain (GP), feed intake (CR), feed: gain (CA), bone fracture resistance (BFR), ashes (AO) and phosphorus in the bone (PO) were the evaluated variables. The available phosphorus requirements were estimated by means of the regression polynomial and linear response plateau models. The supplemented levels of available phosphorus affected the GP, CR, CA, BFR, AO and PO, for males and females. The requirement estimates of available phosphorus ranged from $0,259(.089 \% / \mathrm{Mcal} \mathrm{ME})$ to $.559 \%(.184 \% / \mathrm{Mcal}$ of $\mathrm{ME}$ ), for males and from .307\% (.092\%/Mcal ME) to .575\% (.190\%/Mcal ME) for females. However, according to the biological values, for the performance and bone variables, it can be suggested that available phosphorus requirements, for male and female broilers, from 1 to 21 days of age, is $.45 \%$ or $.148 \%$ /Mcal ME.
\end{abstract}

Key Words: available phosphorus requirement, broilers, initial phase

\section{Introdução}

Várias pesquisas têm sido desenvolvidas para determinar as exigências nutricionais das aves em diferentes idades, sexo e linhagens, com objetivo de se obter alimentação de menor custo, que permita o máximo aproveitamento do potencial genético da ave.

O fósforo é indicado como o terceiro nutriente mais caro em uma ração para monogástricos, ficando atrás somente da energia e da proteína, particularmente dos aminoácidos sulfurados e da lisina (BOLLING et al., 2000). O fósforo, entre suas principais funções, é considerado elemento essencial para a formação da estrutura óssea, participa da formação de membranas celulares, é componente dos ácidos nucléicos envolvidos no crescimento e na diferenciação celular, participa na manutenção do equilíbrio osmótico e eletrolítico, é essencial para utilização e transferência de energia (na forma de ATP), necessário para a formação dos fosfolipídeos, o transporte de gorduras e a síntese de

\footnotetext{
${ }^{1}$ Parte da tese de Mestrado do primeiro autor.

${ }^{2}$ Mestre em Zootecnia, DZO, UFV, Viçosa MG.

3 Professor do Departamento de Zootecnia, DZO, UFV, Viçosa - MG. Pesquisador do CNPq.

${ }^{4}$ Professor da UNIOESTE, estudante do curso de Doutorado, DZO, UFV, Viçosa - MG.
} 
aminoácidos e proteínas, e, ainda, participa no controle do apetite e na eficiência alimentar.

O fósforo vem sendo objetivo de muitas pesquisas mundiais, devido não somente a sua importância econômica, mas também a sua importância ambiental. Pelo fato de os animais consumirem grande quantidade desse mineral, ele também é eliminado, pelas fezes e pela urina, em grande quantidade no meio ambiente, o que vem causando, em alguns países, preocupação com o excesso desse mineral no solo, podendo causar problemas como a contaminação do solo e de lençóis freáticos.

Com o objetivo de diminuir a excreção de fósforo pelos animais, muitos autores como LESKE e COON ( 1999 ), vêm pesquisando efeito do uso da fitase em vários ingredientes utilizados em rações, visando com isso melhorar a utilização do fósforo fítico pelos animais e também diminuir a necessidade de suplementação do fósforo por meio de fontes inorgânicas.

Devido à grande importância biológica do fósforo, o seu fornecimento como nutriente essencial nas rações tem sido constantemente pesquisado. Com a constante evolução genética das aves, os estudos sobre exigências nutricionais devem ser realizados periodicamente.

A exigência nutricional de fósforo disponível para frangos de corte, para o período de 1 a 21 dias de idade, segundo ROSTAGNO et al. (1983), NATIONAL RESEARCH CONCIL - NRC (1994) e ROSTAGNO et al (1996), é de, respectivamente, $0,167,0,151 ; 0,141 \%$ de $\mathrm{P}$ disp/Mcal de energia metabolizável, para o período de 1 a 28 dias de idade.

O esqueleto de um animal é constituído de estruturas com vasos sangüíneos, linfáticos e nervos. Cerca de um terço do osso consiste de uma estrutura orgânica de tecido fibroso e células e os outros dois terços, de sais inorgânicos em que o fosfato de cálcio totaliza cerca de $80 \%$ (SISSON e GROSSMAN, 1981).

Os ossos, além de serem componentes estruturais ou de suporte do corpo, servem como reserva de cálcio e fósforo e podem ser mobilizados ocasionalmente, quando o fornecimento desses minerais for inadequado para atender as necessidades do organismo (MAYNARD e LOOSLI, 1984).

Inúmeras funções podem ser atribuídas ao fósforo no organismo animal. Segundo UNDERWOOD (1981), o fósforo, além de participar como um dos principais componentes do tecido ósseo e dos dentes, ainda atua como componente dos ácidos nucléicos (DNA e RNA), que são essenciais para o crescimento e a diferenciação celular, e, juntamente com outros elementos, participa na manutenção da pressão osmótica e do equilíbrio ácido-básico. Entre suas funções metabólicas, participa na utilização e transferência de energia, nas formas de adenosina mono, di e tri-fosfato e na formação dos fosfolipídeos, tendo como conseqüência participação no transporte de ácidos graxos, absorção e deposição de gorduras. O fósforo participa também da formação de proteínas, sendo muito importante em todas as fases de reprodução do animal. O autor cita ainda que o fósforo atua influenciando o apetite e a eficiência de utilização dos alimentos de forma ainda não totalmente conhecida.

Vários autores, como LIBAL et al. (1969), KOCH et al. (1984) e GOMES et al. (1993), relataram que o requerimento de fósforo para otimizar o desempenho é inferior àquele requerido para maximizar o desenvolvimento dos ossos. O mesmo foi verificado por GOMES et al. (1994), que, trabalhando com frangos de corte nas fases de crescimento e terminação, encontraram maior valor de exigência de fósforo disponível para maximizar o desenvolvimento dos ossos do que para otimizar o ganho de peso, na fase de crescimento, sendo que para a fase de terminação os valores de exigência de fósforo disponível foram semelhantes, quando estimados por meio de variáveis como ganho de peso e cinza e fósforo no osso.

Segundo DALE (1983), a inclusão de altos níveis de cálcio nos alimentos aumenta a necessidade de fósforo para frangos de corte. O cálcio interfere na absorção do fósforo, complexando-o em nível de intestino, tornado-o, assim, menos disponível, além de dificultar a absorção de fósforo fítico pela ave.

Sabe-se que o conteúdo de energia da dieta influencia o consumo de ração, portanto, deve-se manter uma relação entre o teor de energia das rações e todos os nutrientes necessários ao animal, para que seja garantido o consumo desses nutrientes em quantidades adequadas para o bom desempenho dos animais.

Com o constante melhoramento genético das aves, as linhagens de frangos de corte têm adquirido capacidade de expressar cada vez mais rápido seu alto potencial produtivo. Porém, esse potencial produtivo só é eficientemente aproveitado, quando se tem, além de outros fatores, fornecimento adequado de todos os nutrientes exigidos pela ave.

No que se refere às necessidades de minerais para aves, os macrominerais como cálcio e fósforo aparecem como os mais limitantes. O fósforo tem sido alvo de grande número de trabalhos, nos quais se procura avaliar a exigência nutricional de fósforo das 
aves, considerando-se as diferentes linhagens, o sexo, o consumo de ração e as relações do fósforo com todos os outros nutrientes das rações.

DAMRON e FLUNKER (1991), avaliando a suplementação de fósforo, para frangos de corte de até 21 dias de idade, comparando o fosfato bicálcico e o fosfato monoamônio líquido, na água de bebida verificaram que o fosfato monoamônio na água de bebida foi excelente fonte de fósforo para os animais, apresentando resultados de desempenho semelhantes ao fosfato bicálcico.

As recomendações dos níveis de exigência de fósforo, para frangos de corte, são muito variadas. GOMES et al. (1993), utilizando uma ração basal de milho e farelo de soja com $0,43 \%$ de fósforo, suplementada com cinco níveis de fósforo, 0,$0 ; 0,08$; 0,$16 ; 0,24 ;$ e $0,32 \%$, determinaram a exigência nutricional de fósforo para frangos de corte de até 21 dias de idade e observaram que os valores de exigência de fósforo variaram de $0,30 \%$ ou $0,098 \%$ /Mcal de EM, para ganho de peso, a $0,43 \%$ ou $0,141 \%$ /Mcal de EM, para fósforo no osso. Esses autores sugeriram que a exigência média de fósforo fosse de $0,385 \%$ ou $0,125 \% / M c a l$ de EM, a qual está pouco abaixo da recomendada pelo NRC (1994), 0,141\%/Mcal de EM.

PARMER et al. (1987), estudando os efeitos da deficiência de fósforo na dieta, para machos de corte do $10^{0}$ ao 29 - dia, utilizandoníveis de 0,05 e $0,10 \%$ de fósforo disponível, relataram que esses animais cresceram mais lentamente e se alimentaram menos que os animais submetidos à dieta controle com $0,65 \%$ de fósforo disponível. Além do menor consumo, os autores constataram ainda que as aves apresentaram hipocalcemia, hipofosfatemia e decréscimo na porcentagem de cinza, nopeso, nocomprimentoe naespessura doossotibiotarsal.

JUNQUEIRA et al. (1993) compararam a farinha de carne e ossos com o fosfato bicálcico, como fonte de fósforo na ração, para frangos de corte, utilizando níveis de $0,7 \%$ de fósforo total (PT) para a fase de 1 a 28 dias e níveis de 0,$7 ; 0,6$; e $0,5 \%$ de fósforo total para o período de 29 a 40 dias. Os resultados indicaram que a farinha de carne e ossos, ou o fosfato bicálcico, não afetaram o desenvolvimento das aves de 1 a 28 dias, quando se utilizou o nível de $0,7 \%$ de PT.

BELLAVER et al. (1987) verificaram que frangos de corte alimentados com uma ração basal contendo $0,41 \%$ de fósforo disponível, com suplementação de 0,$0 ; 0,15 ; 0,30 ;$ e $0,45 \%$ de $\mathrm{P}$, proveniente do fosfato bicálcico, reduziram a conversão alimentar, à medida que se elevaram os níveis de fósforo na ração, na fase de 7 a 28 dias de idade.
ROSTAGNO et al. (1988), trabalhando com fêmeas de corte na fase inicial, de 1 a 21 dias, para determinar a exigência nutricional de fósforo disponível, utilizaram uma ração basal com baixo nível de fósforo: $0,38 \%$ de PT ou $0.168 \%$ de P-disp., suplementada com quatro níveis de fósforo disponível: 0,$0 ; 0,1 ; 0,2 ;$ e $0,3 \%$. Os autores concluíram que a exigência nutricional de $\mathrm{P}$ disp, para fêmeas, variou de 0,303 , para ganho de peso, a $0,392 \%$, para porcentagem de fósforo no fêmur, sendo o valor médio de $0,349 \%$ ou $0,122 \%$ /Mcal de EM.

O objetivo do presente trabalho foi estabelecer a exigêncianutricional de fósforo disponível parafrangos de corte machos e fêmeas, durante a fase inicial (1 a 21 dias).

\section{Material e Métodos}

O presente trabalho foi conduzido no Setor de Avicultura do Departamento de Zootecnia da Universidade Federal de Viçosa (UFV), no período de 05 de junho até 26 de julho de 1997.

O experimento foi realizado utilizando um total de 960 pintos de um dia de idade, da marca comercial, Hubbard, sendo metade machos e metade fêmeas, de 1 a 21 dias de idade. As aves apresentaram peso inicial médio de 42,5 e 42,1g, para machos e fêmeas, respectivamente, e foram vacinadas contra Bouba Aviária e doença de Marek no incubatório.

A distribuição dos tratamentos foi realizada ao acaso, em 48 boxes de 1,50 x 1,50 m, com piso de cimento, coberto com cepilhos de madeira. Utilizaram-se dois galpões de alvenaria, com dimensões de 4,50 x 19,40 m e 2,80 m de pé-direito, cobertos com telhas de cimento amianto, com lanternim, laterais possuindo muretas de $0,50 \mathrm{~m}$ de altura e o restante fechado com tela de 1/2", à prova de pássaros e cortinas plásticas com abertura de baixo para cima.

Adotou-se um programa de luz contínuo, 24 horas de luz (natural + artificial), durante todo o período experimental, utilizando-se lâmpadas de $60 \mathrm{~W}$. Para o aquecimento das aves foram utilizadas lâmpadas infravermelho de 250W/box, com altura regulável, para manter a temperatura em torno da requerida pelas aves, durante este período.

A temperatura diária, observada no interiordos galpões por intermédio de termômetros de máxima e mínima, durante todo o período experimental, consta da Tabela 1.

A composição química dos ingredientes utilizados na formulação das dietas experimentaisencontra-senaTabela 2.

Foi utilizado odelineamento experimental emblocos casualizados (bloco = galpão), com seis tratamentos, dois sexos, quatro repetições por sexo e 20 aves por 
unidade experimental. A dieta basal (Tabela 3) foi formulada para atender às exigências das aves, segundo as recomendações de ROSTAGNO et al. (1996), exceto para o fósforo disponível, que permaneceu deficiente, em nível de $0,150 \%$.

Os tratamentos consistiram dos níveis de suplementação de fósforo disponível, provenientes do fosfato bicálcico, em 0,$0 ; 0,10 ; 0,20 ; 0,30 ; 0,40 ; \mathrm{e}$ $0,50 \%$, resultando em um total de 0,$15 ; 0,25 ; 0,35$; 0,$45 ; 0,55$; e $0,65 \%$ de fósforo disponível. As suplementações com os níveis de fósforo disponível foram feitas em substituição ao caulim, usado como inerte nas dietas experimentais.

As aves foram pesadas no $1 \underline{\mathrm{o}}$ e $21 \underline{\mathrm{o}}$ dia de idade, para avaliação de ganho de peso, consumo de ração e conversão alimentar.

Três aves na média de peso de cada repetição, totalizando 24 aves por tratamento, em um total de

Tabela 1 - Temperatura no interior dos galpões durante o período de 1 a 21 dias de idade

Table 1 - Temperature in the poultry-sheds, from1 to 21 days age Temperatura do $\operatorname{ar}\left({ }^{\circ} \mathrm{C}\right) \quad$ Galpão-1 $\quad$ Galpão-2 $\quad$ Média Temperature of air $\left({ }^{\circ} \mathrm{C}\right) \quad$ Poultry Poultry geral

$\begin{array}{ccc}\text { shed }-1 \quad \text { shed }-12 \text { Overall } & \text { oultry }\end{array}$

\begin{tabular}{lccc}
\hline $\begin{array}{l}\text { Máxima média } \\
\text { Average maximun }\end{array}$ & 27,0 & 26,4 & 26,7 \\
$\begin{array}{l}\text { Mínima média } \\
\text { Average minimun }\end{array}$ & 15,4 & 12,4 & 13,9 \\
$\begin{array}{l}\text { Máxima absoluta } \\
\text { Maximun absolute }\end{array}$ & 32,0 & 30,0 & - \\
$\begin{array}{l}\text { Mínima absoluta } \\
\text { Minimun absolute }\end{array}$ & 8,0 & 4,0 & - \\
\hline
\end{tabular}

Tabela 2 - Teores de proteína bruta, cálcio e fósforo total dos ingredientes utilizados nas dietas experimentais

Table 2 - Crude protein, calcium and total phosphorus contents in the ingredients used in experimental diets

\begin{tabular}{|c|c|c|c|}
\hline $\begin{array}{l}\text { Ingredientes } \\
\text { Ingredients }\end{array}$ & $\begin{array}{c}\text { Proteína } \\
\text { bruta }(\%) \\
\text { Crude protein }\end{array}$ & $\begin{array}{l}\text { Cálcio (\%) } \\
\text { Calcium }\end{array}$ & $\begin{array}{c}\text { Fósforo (\%) } \\
\text { Phosphorus }\end{array}$ \\
\hline $\begin{array}{l}\text { Milho } \\
\text { Corn }\end{array}$ & 7,87 & 0,025 & 0,246 \\
\hline $\begin{array}{l}\text { Farelo de soja } \\
\text { Soybean meal }\end{array}$ & 45,96 & 0,330 & 0,615 \\
\hline $\begin{array}{l}\text { Calcário } \\
\text { Limestone }\end{array}$ & - & 39,20 & - \\
\hline $\begin{array}{l}\text { Fosfato bicálcico } \\
\text { Dicalcium phosphat }\end{array}$ & te & 24,23 & 18,69 \\
\hline
\end{tabular}

Tabela 3 - Composição percentual da dieta basal para a fase de 1 a 21 dias

Table 3 - Percentage composition of the experimental diets from 1 to 21 days

Ingredientes $(\mathrm{kg})$

Ingredients

\begin{tabular}{|c|c|}
\hline Milho & 56,500 \\
\hline \multicolumn{2}{|l|}{ Corn } \\
\hline Farelo de soja & 36,300 \\
\hline \multicolumn{2}{|l|}{ Soybean meal } \\
\hline Óleo vegetal & 3,000 \\
\hline \multicolumn{2}{|l|}{ Vegetable oil } \\
\hline Caulim(Inerte) & 1,140 \\
\hline \multicolumn{2}{|l|}{ Kaolin (Complement) } \\
\hline Fosfato bicálcico & 0,170 \\
\hline \multicolumn{2}{|l|}{ Dicalcium phosphate } \\
\hline Calcário & 2,110 \\
\hline \multicolumn{2}{|l|}{ Limestone } \\
\hline Cloreto de colina & 0,100 \\
\hline \multicolumn{2}{|l|}{ Choline chloride } \\
\hline DL-Metionina (99\%) & 0,150 \\
\hline \multicolumn{2}{|l|}{ DL-Methionine } \\
\hline Anticoccidiano $^{3}$ & 0,050 \\
\hline \multicolumn{2}{|l|}{ Anticoccidial agents } \\
\hline Promotor de crescimento & 0,020 \\
\hline \multicolumn{2}{|l|}{ Growth promoter } \\
\hline BHT & 0,010 \\
\hline Sal & 0,300 \\
\hline \multicolumn{2}{|l|}{ Salt } \\
\hline Suplemento mineral $^{1}$ & 0,050 \\
\hline \multicolumn{2}{|l|}{ Supplement mineral } \\
\hline Suplemento vitamínico 2 & 0,100 \\
\hline \multicolumn{2}{|l|}{ Supplement vitamin } \\
\hline \multicolumn{2}{|l|}{ Calculated values } \\
\hline $\mathrm{EM}(M E), \mathrm{mcal} / \mathrm{kg}$ & 3,030 \\
\hline Proteína bruta, $\%$ & 21,13 \\
\hline \multicolumn{2}{|l|}{ Crude protein } \\
\hline Fósforo disponível, \% & 0,150 \\
\hline \multicolumn{2}{|l|}{ Available phosphorus } \\
\hline Cálcio, \% & 1,002 \\
\hline \multicolumn{2}{|l|}{ Calcium } \\
\hline Metionina, \% & 0,480 \\
\hline \multicolumn{2}{|l|}{ Methionine } \\
\hline Met + Cist, $\%$ & 0,833 \\
\hline \multicolumn{2}{|l|}{$M e t+C y s$} \\
\hline Lisina, $\%$ & 1,172 \\
\hline \multicolumn{2}{|l|}{ Lysine } \\
\hline Treonina, $\%$ & 0,838 \\
\hline \multicolumn{2}{|l|}{ Threonine } \\
\hline Arginina, $\%$ & 1,443 \\
\hline \multicolumn{2}{|l|}{ Arginine } \\
\hline Triptofano, $\%$ & 0,288 \\
\hline \multicolumn{2}{|l|}{ Tryptophan } \\
\hline 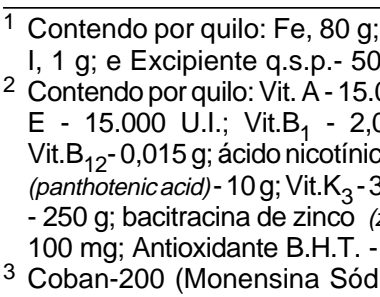 & $\begin{array}{l}60 \mathrm{~g} ; \mathrm{Zn}, 50 \mathrm{~g} \text {; } \\
000.000 \text { U.l.; Vit. } \\
\text { Vit. } \mathrm{B}_{6}-3,0 \mathrm{~g} \text {; } \\
\text { cido pantotênico } \\
\text { :id) - } 1,0 \mathrm{~g} ; \text { Colina } \\
\text { lênio (selenium) - } \\
\text { p. - } 1000 \mathrm{~g} \text {. }\end{array}$ \\
\hline
\end{tabular}


Rev. bras. zootec.

144 aves, foram abatidas por deslocamento cervical, sendo retiradas as tíbias para determinação de resistência à quebra e análise da quantidade fósforo e matéria mineral (cinzas) nos ossos.

As análises dos teores de cinzas e fósforo nos ossos foram realizadas de acordo com a metodologia proposta por SILVA (1980) e as de resistência dos ossos à quebra, utilizando-se os ossos in natura em um aparelho que mede a força de resistência de materiais (INSTRON- modelo 4204).

As análises estatísticas dos resultados obtidos foram realizadas de acordo com o programa SAEG (Sistema para Análise Estatística e Genética), versão 5.0, desenvolvido pela UNIVERSIDADE FEDERAL DE VIÇOSA - UFV (1982). As estimativas de exigência de fósforo foram feitas utilizando-se os modelos quadráticos e, ou, "Linear Response Plateou" (LRP), descrito por BRAGA (1983), conforme ajustamento dos dados obtidos para cada variável, interpretando-se as respostas biológicas das aves.

O modelo estatístico utilizado foi:

$$
\mathrm{Y}_{\mathrm{ijkl}}=\mu+\mathrm{S}_{\mathrm{i}}+\mathrm{T} / \mathrm{S}_{\mathrm{ij}}+\mathrm{B}_{1}+\hat{\mathrm{I}}_{\mathrm{ijkl}}
$$

em que $Y_{i j k l}$ é produção observada na unidade experimental $\mathrm{k}$, do nível de fósforo disponível $\mathrm{j}$, do sexo i e do bloco 1; $\mu$, média geral; $S_{i}$, efeito de sexo i (i=1 e 2); $\mathrm{T} / \mathrm{S}_{\mathrm{ij}}$, efeito dos níveis de fósforo disponível $\mathrm{j}$ dentro do sexo $\mathrm{i}$; $\mathrm{B}_{1}$, efeito do bloco $1(\mathrm{l}=1 \mathrm{e} 2)$; e $\hat{\mathrm{I}}_{\mathrm{ijk}}$, erro aleatório associado a cada observação.

\section{Resultados e Discussão}

Ganho de peso, consumo de ração e conversão alimentar

Os resultados de desempenho estão apresentados na Tabela 4.

Houve efeito $(\mathrm{P}<0,01)$ dos níveis de fósforo disponível nas dietas, durante o período de 1 a 21 dias, sobre o ganho de peso, o consumo de ração e a conversão alimentar dos machos e das fêmeas.

Quando se analisam os resultados de ganho de peso (Tabela 4), pode-se observar que tanto a deficiência quanto o excesso de fósforo disponível foram prejudiciais para o desenvolvimento das aves. Isto está de acordo com PARMER et al. (1987), os quais constataram que a deficiência de fósforo disponível, para frangos de corte de 10 a 29 dias de idade, acarretou severa redução no peso das aves e no consumo de ração. Os autores sugerem que a deficiência de fósforo pode causar redução no desempenho das aves principalmente pela diminuição no consumo de ração, porém há severa redução na síntese e liberação de hormônios de crescimento e hormônios da tireóide, principalmente $\mathrm{T}_{3}$.

SHAFEY e McDONALD et al. (1991) constataram que o excesso de fósforo e cálcio na dieta pode reduzir o desempenho das aves, em função de dimi-

Tabela 4 - Efeito dos níveis de fósforo disponível na dieta sobre o desempenho de frangos de corte machos (M) e fêmeas (F), no período de 1 a 21 dias de idade

Table 4 - Effects of available phosphorus dietary levels on male (M) and female broilers performance (F), from 1 to 21 days old

\begin{tabular}{|c|c|c|c|c|}
\hline $\begin{array}{l}\mathrm{P} \text { disponível (\%) } \\
\text { Available P level }\end{array}$ & $\begin{array}{l}\text { Sexo } \\
\text { Sex }\end{array}$ & $\begin{array}{c}\text { Ganho de peso (g) } \\
\text { Weightgain }\end{array}$ & $\begin{array}{c}\text { Consumo de ração (g) } \\
\text { Feed intake }\end{array}$ & $\begin{array}{l}\text { Conversão alimentar } \\
\text { Feed:gain ratio }\end{array}$ \\
\hline 0,150 & $\mathrm{M}$ & 240 & 509 & 2,14 \\
\hline 0,250 & M & 502 & 875 & 1,74 \\
\hline 0,350 & M & 636 & 1094 & 1,72 \\
\hline 0,450 & M & 689 & 1165 & 1,69 \\
\hline 0,550 & M & 686 & 1154 & 1,68 \\
\hline 0,650 & M & 672 & 1151 & 1,71 \\
\hline Média (Mean) & & 571 & 991 & 1,78 \\
\hline 0,150 & $\mathrm{~F}$ & 271 & 546 & 2,02 \\
\hline 0,250 & $\mathrm{~F}$ & 483 & 879 & 1,82 \\
\hline 0,350 & $\mathrm{~F}$ & 570 & 1029 & 1,80 \\
\hline 0,450 & $\mathrm{~F}$ & 613 & 1024 & 1,67 \\
\hline 0,550 & $\mathrm{~F}$ & 615 & 1057 & 1,72 \\
\hline 0,650 & $\mathrm{~F}$ & 615 & 1064 & 1,73 \\
\hline Média (Mean) & & 528 & 933 & 1,79 \\
\hline \multicolumn{5}{|l|}{ P disponível (\%) } \\
\hline \multirow[t]{2}{*}{ Available P (\%) } & M & $* *$ & $* *$ & $* *$ \\
\hline & $\mathrm{F}$ & $* *$ & $* *$ & $* *$ \\
\hline $\mathrm{CV}(\%)$ & & 5,15 & 5,38 & 7,15 \\
\hline
\end{tabular}

** Efeito quadrático $(P<0,01)$ pelo teste $F$.

${ }^{* *}$ Quadratic effect $(P<.01)$ by $F$ test. 
nuição na digestibilidade da maioria dos aminoácidos, inclusive alguns aminoácidos essenciais como metionina, lisina e arginina. Esta redução na digestibilidade dos aminoácidos, segundo Shafey (1988), citado por SHAFEY e McDONALD (1991), é atribuída a aumento da microflora intestinal, o que pode levar à diminuição da absorção dos nutrientes pela parede intestinal e, ainda, da permeabilidade dos aminoácidos em relação à parede intestinal. Esse fato pode ocorrer devido à redução da superfície de absorção da parede intestinal. Além disso, o excesso de cálcio e fósforo na dieta pode resultar em redução na disponibilidade desses minerais pela formação de fosfatos de cálcio, insolúvel no trato digestível, o que, conseqüentemente, reduz a absorção de ambos. Entretanto, de acordo com os resultados observados na Tabela 4, verificou-se que houve pequena variação numérica no ganho de peso e na conversão alimentar, quando o nível de fósforo variou de 0,45 a $0,65 \%$, o que corrobora os resultados encontrados por NELSON et al. (1992) e BRUGALLI (1996).

Observou-se que houve melhora da conversão alimentar, à medida que o nível de fósforo disponível aumentou de 0,15 para $0,45 \%$ nas dietas. O nível de $0,65 \%$ de fósforo resultou em pior conversão alimentar, evidenciando que o excesso de fósforo reduziu a utilização dos nutrientes pelas aves. Resultados se- melhantes foram obtidos por WALDROUP et al. (1975), que verificaram redução na eficiência alimentar de frangos de corte recebendo dietas deficientes ou com excesso de fósforo disponível, de 1 a 28 dias de idade, e BELLAVER et al. (1987), que observaram efeito negativo na conversão alimentar causado pelo excesso de fósforo na dieta. Porém, ROSTAGNO et al. (1988) não encontraram diferenças para conversão alimentar de frangos de corte fêmeas, de 1 a 21 dias de idade, recebendo dietas contendo 0,168 a $0,468 \%$ de fósforo disponível. Segundo SHAFEY et al. (1990), o excesso de cálcio e fósforo reduziu significativamente o ganho de peso das aves, porém não prejudicou a conversão alimentar.

Resistência da tíbia à quebra, cinza e fósforo na tíbia

Os resultados de resistência da tíbia à quebra e de cinza e fósforo na tíbia estão apresentados na Tabela 5 .

Houve efeito quadrático $(\mathrm{P}<0,01)$ do nível de fósforo na dieta sobre cinza e fósforo nos ossos (\% e g) e da resistência da tíbia à quebra, tanto para os machos como para as fêmeas.

Verificou-se que a tíbia nos machos apresentou maior resistência à quebra e menor porcentagem de matéria mineral e fósforo do que nas fêmeas. Estes resultados indicam que, em média, as fêmeas tiveram maior capacidade em depositar minerais nos ossos que os machos, apesar de apresentarem menor resis-

Tabela 5 - Efeito dos níveis de fósforo disponível na dieta sobre a resistência do osso à quebra (ROQ) e os teores de cinza (CO) e fósforo (PO) nos ossos, de frangos de corte machos (M) e fêmeas (F), durante o período de 1 a 21 dias de idade

Table 5 - Effects of available phosphorus dietary levels on bone fracture resistance (BFR), ash (CO) and bone phosphorus contents (PB) of male $(M)$ and female $(F)$ broilers, from 1 to 21 days old

\begin{tabular}{|c|c|c|c|c|c|c|}
\hline \multirow{2}{*}{$\begin{array}{l}\text { P disponível (\%) } \\
\text { Available P level }\end{array}$} & \multirow{2}{*}{$\begin{array}{l}\text { Sexo } \\
\text { Sex }\end{array}$} & \multirow{2}{*}{$\begin{array}{c}\mathrm{ROQ}(\mathrm{kgf} / \mathrm{mm}) \\
R O Q\end{array}$} & \multicolumn{2}{|c|}{$\mathrm{CO}$} & \multicolumn{2}{|c|}{$\mathrm{PO}$} \\
\hline & & & $(\%)$ & (g) & $(\%)$ & $(\mathrm{g})$ \\
\hline 0,150 & $\mathrm{M}$ & 3,52 & 23,15 & 0,78 & 3,61 & 0,12 \\
\hline 0,250 & M & 9,68 & 29,42 & 1,57 & 4,00 & 0,21 \\
\hline 0,350 & M & 19,70 & 36,21 & 2,29 & 6,36 & 0,40 \\
\hline 0,450 & M & 26,02 & 38,85 & 2,71 & 6,81 & 0,48 \\
\hline 0,550 & M & 23,58 & 37,73 & 2,61 & 6,33 & 0,44 \\
\hline 0,650 & M & 23,15 & 36,98 & 2,50 & 6,87 & 0,46 \\
\hline Média (Mean) & & 17,61 & 33,72 & 2,08 & 5,66 & 0,35 \\
\hline 0,150 & $\mathrm{~F}$ & 3,68 & 26,41 & 0,76 & 3,96 & 0,11 \\
\hline 0,250 & $\mathrm{~F}$ & 10,47 & 30,48 & 1,42 & 5,36 & 0,25 \\
\hline 0,350 & $\mathrm{~F}$ & 19,81 & 38,36 & 1,93 & 6,64 & 0,33 \\
\hline 0,450 & $\mathrm{~F}$ & 20,28 & 38,79 & 2,71 & 6,99 & 0,48 \\
\hline 0,550 & $\mathrm{~F}$ & 19,00 & 37,12 & 2,12 & 6,40 & 0,36 \\
\hline 0,650 & $\mathrm{~F}$ & 21,96 & 38,04 & 2,14 & 7,41 & 0,42 \\
\hline Média (Mean) & & 15,86 & 34,86 & 1,85 & 6,13 & 0,32 \\
\hline P disponível (\%) & $\mathrm{M}$ & $* *$ & $* *$ & $* *$ & $* *$ & $* *$ \\
\hline Available P (\%) & $\mathrm{F}$ & ** & $* *$ & $* *$ & ** & $* *$ \\
\hline $\mathrm{CV}(\%)$ & & 21,90 & 2,37 & 8,38 & 10,60 & 8,27 \\
\hline
\end{tabular}

** Efeito quadrático $(P<0,01)$ pelo teste $F$.

** Quadratic effect $(P<.01)$ by $F$ test. 
Rev. bras. zootec.

tência à quebra, caracterizando o fato de que o maior teor de cinza e fósforo nos ossos não resultou em maior resistência à quebra óssea.

Observou-se aumento para o teor de minerais nos ossos, à medida que se elevou o nível de fósforo disponível na dieta de 0,15 a $0,45 \%$ de P-disp, tanto para os machos quanto para as fêmeas, porém houve pequena variação no teor de cinzas, quando se elevou o nível de fósforo disponível de 0,45 a 0,65\%. Este resultado está de acordo com LIMA (1995), que encontrou valores crescentes de cinzas no fêmur, à medida que se elevou o nível de fósforo disponível na dieta de 0,151 a $0,446 \%$, verificando pouca alteração quando este nível foi aumentado para $0,544 \%$, e GOMES et al. (1993), que verificaram valores crescentes para cinzas na tíbia até o nível de $0,34 \%$ de fósforo disponível, permanecendo constantes quando se elevaram os níveis para 0,42 e $0,50 \%$.

Quando se analisou a variável fósforo no osso, verificou-se que houve maior deposição de fósforo, quando que se elevou o nível de fósforo disponível da dieta até o nível de $0,45 \%$, tanto para os machos como para as fêmeas. Este resultado está de acordo com os encontrados por ROSTAGNO et al. (1988), GOMES et al. (1993) e LIMA (1995).

Os valores de resistência da tíbia à quebra foram crescentes com o aumento da quantidade de fósforo na dieta de 0,15 a $0,45 \%$. Estes resultados concordam com BRUGALLI (1996), que verificou efeito semelhante para a resistência da tíbia à quebra, quando os níveis de fósforo disponível aumentaram de 0,15 a $0,55 \%$, obtendo o melhor resultado para o nível de 0,45\% de P-disp, e LIMA (1995), que observou aumento linear na resistência à quebra do fêmur, quando os níveis de P-disp variaram de 0,151 a $0,446 \%$, não constatando diferença entre os níveis de 0,446 e $0,544 \%$.

Pode-se observar, de acordo com os níveis de fósforo disponível utilizados nas dietas, que houve amplitude variada na relação cálcio:fósforo para cada tratamento. Os níveis de 0,15 e $0,25 \%$ de P-disp, além de deficientes em fósforo, apresentaram relação cálcio:fósforo disponível muito superior a 2:1, a qual é normalmente utilizada para frangos de corte. Este fato pode ter contribuído para os piores resultados de desempenho e características ósseas encontrados nestes tratamentos, evidenciando que o excesso de cálcio na dieta pode diminuir a absorção do fósforo. Resultados semelhantes também foram obtidos por LIMA (1995) e BRUGALLI (1996), os quais verificaram piores resultados de desempenho para os tratamentos que apresentaram alta relação cálcio:fósforo disponível.

\section{Exigências de fósforo disponível}

As estimativas de exigência de fósforo disponível, para machos e fêmeas, estão apresentadas nas Tabelas 6, 7, 8 e 9 .

As exigências de fósforo disponível variaram, para os machos, de $0,48 \%$, para conversão alimentar a $0,559 \%$, para fósforo em gramas na tíbia, utilizando o modelo quadrático, enquanto pelo modelo LRP de 0,26 , para conversão alimentar, a $0,41 \%$, para resistência da tíbia à quebra. Para as fêmeas, os valores de exigência variaram de $0,51 \%$, para conversão alimentar, a 0,575\%, para porcentagem de fósforo na tíbia, utilizando o modelo quadrático, ao passo que pelo modelo LRP de 0,307\%, para ganho de peso, a $0,437 \%$, para porcentagem de cinzas na tíbia. Estes resultados estão de acordo com vários autores (ROSTAGNO et al., 1988; ABREU, 1989; GOMES et al., 1994; LIMA, 1995; e BRUGALLI, 1996), os quais citam que a exigência de fósforo é maior para maximizar parâmetros ósseos do que para otimizar valores de desempenho.

De acordo com MORRIS (1983), o ajuste de dados pelo LRP em casos especiais proporciona bom ajuste estatístico mas freqüentemente subestima a dose ótima, além disso, o modelo considera a resposta decrescente que pode ocorrer, quando se utilizam níveis mais altos de determinado nutriente, não sendo recomendado para uso prático. Esse autor afirma ainda que o uso do modelo quadrático pode também não proporcionar bom ajuste dos dados, causando falsa segurança, uma vez que a curvatura é muito sensível a variações nos intervalos dos tratamentos e o modelo é fisiologicamente incorreto, pois pressupõe respostas simétricas para a deficiência e o excesso.

De acordo com os resultados obtidos, notou-se que houve superestimação dos valores de exigência de fósforo, obtidos pelo modelo quadrático, e o LRP subestimou os níveis ideais de fósforo para maximizar ganho de peso, conversão alimentar, resistência do osso à quebra e teores de cinza e fósforo no osso das aves, que atingiram valores adequados em nível de $0,45 \%$ de $\mathrm{P}$ disp; a partir daí, obteve-se um platô para os níveis adicionais de fósforo disponível na dieta.

Contudo, as exigências de fósforo disponível, para frangos de corte na fase inicial variaram de $0,259 \%$ ou 0,085\%/Mcal de EM a 0,559\% ou 0,184\%/Mcal de EM para os machos e, para as fêmeas, de $0,307 \%$ ou 0,092\%/Mcal de EM a 0,575\% ou 0,190\%/Mcal de EM. 
Tabela 6 - Exigência de fósforo disponível para frangos de corte machos e fêmeas, de 1 a 21 dias de idade, considerando as variáveis de desempenho estimadas pelo modelo quadrático

Table 6 - Available phosphorus requirement, for male and female broilers, from 1 to 21 days old, considering the performance estimated by the quadratic model

\begin{tabular}{|c|c|c|c|c|c|c|}
\hline \multirow{2}{*}{$\begin{array}{l}\text { Variáveis } \\
\text { Variable } \\
\text { Desempenho }\end{array}$} & $\begin{array}{c}\text { Equação da regressão } \\
\text { Regression equation }\end{array}$ & $\begin{array}{l}\text { Resp. máx. } \\
\text { Max. point }\end{array}$ & \multicolumn{2}{|c|}{$\begin{array}{c}\text { Exigências } \\
\text { Requeriments } \\
(\%)(\% / \text { Mcal EM })\end{array}$} & $\mathrm{R}^{2 *}$ & $\begin{array}{l}\text { SQD } \\
S S D\end{array}$ \\
\hline & & & & & & \\
\hline $\begin{array}{l}\text { Machos } \\
\text { Male }\end{array}$ & & & & & & \\
\hline $\begin{array}{l}\text { Ganho de peso } \\
\text { Weigth gain }\end{array}$ & $\hat{Y}=-195,505+3545,30 X-3444,66 X^{2}$ & 716,615 & 0,520 & 0,172 & 0,98 & 2417,972 \\
\hline $\begin{array}{l}\text { Conversão alimentar } \\
\text { Feed:gain ratio } \\
\text { Fêmeas } \\
\text { Female }\end{array}$ & $\hat{\mathrm{Y}}=2,57873-3,88188 \mathrm{X}+4,00806 \mathrm{X}^{2}$ & 1,638 & 0,480 & 0,158 & 0,86 & 0,0219 \\
\hline $\begin{array}{l}\text { Ganho de peso } \\
\text { Weigth gain }\end{array}$ & $\hat{Y}=-46,096+2619,01 X-2502,69 X^{2}$ & 639,061 & 0,520 & 0,172 & 0,98 & 2249,225 \\
\hline $\begin{array}{l}\text { Conversão alimentar } \\
\text { Feed:gain ratio }\end{array}$ & $\hat{Y}=2,32018-2,43937 X+2,37501 X^{2}$ & 1,694 & 0,510 & 0,168 & 0,93 & 0,00525 \\
\hline
\end{tabular}

* $(\mathrm{P}<0,05)$ pelo teste $\mathrm{F}$.

Estimado pela equação da reta em Newton e resposta máxima em $\mathrm{kgf} / \mathrm{mm}$, em que $1 \mathrm{~N}=0,1020 \mathrm{kgf} / \mathrm{mm}$.

* $(P<.05)$ by $F$ test.

Estimated by the regression equation in Newton and maximum answer in $\mathrm{kgf} / \mathrm{mm}$, where $=.1020 \mathrm{kgf} / \mathrm{mm}$.

Tabela 7 - Exigência de fósforo disponível, para frangos de corte machos e fêmeas, de 1 a 21 dias de idade, considerando as variáveis ósseas, estimadas pelo modelo quadrático

Table 7 - Available phosphorus requirement, for male and female broilers, from 1 to 21 days old, considering the bone variables estimated by the quadratic model

\begin{tabular}{|c|c|c|c|c|c|c|}
\hline $\begin{array}{l}\text { Variáveis } \\
\text { Variable }\end{array}$ & $\begin{array}{l}\text { Equação da regressão } \\
\text { Regression equation }\end{array}$ & $\begin{array}{l}\text { Resp. máx. } \\
\text { Max. point }\end{array}$ & $\begin{array}{r}\mathrm{Ex} \\
\operatorname{Req} \\
(\%)(\%\end{array}$ & $\begin{array}{l}\mathrm{s} \\
\mathrm{ts} \\
\mathrm{EM})\end{array}$ & $\mathrm{R}^{2 *}$ & $\begin{array}{l}\text { SQD } \\
S S D\end{array}$ \\
\hline \multicolumn{7}{|l|}{ Machos (Male) } \\
\hline $\begin{array}{l}\text { Resist. tíbia }{ }^{1} \\
\text { Tibia strength }\end{array}$ & $\hat{Y}=-180,797+1569,22 X-1449,60 X^{2}$ & 24,87 & 0,541 & 0,178 & 0,96 & 1539,445 \\
\hline $\begin{array}{l}\text { Cinza tíbia }(\%) \\
\text { Tibia ash }\end{array}$ & $\hat{Y}=7,08298+122,947 X-119,153 X^{2}$ & 38,80 & 0,515 & 0,170 & 0,99 & 2,779 \\
\hline $\begin{array}{l}\text { Cinza tíbia }(\mathrm{g}) \\
\text { Tibia ash }\end{array}$ & $\hat{Y}=-1,1303+14,6148 X-13,9430 X^{2}$ & 2,70 & 0,524 & 0,173 & 0,99 & 2,319 \\
\hline $\begin{array}{l}\text { Fósforo tíbia (g) } \\
\text { Phosphorus ash } \\
\text { Fêmeas } \\
\text { Female }\end{array}$ & $\hat{Y}=-0,21653+2,46616 X-2,20577 X^{2}$ & 0,47 & 0,559 & 0,184 & 0,95 & 0,00555 \\
\hline $\begin{array}{l}\text { Resist. tíbia }{ }^{1} \\
\text { Tibia strength }\end{array}$ & $\hat{Y}=-98,1123+1085,85 X-996,030 X^{2}$ & 20,18 & 0,546 & 0,180 & 0,77 & 5569,375 \\
\hline $\begin{array}{l}\text { Cinza tíbia }(\%) \\
\text { Tibia ash }\end{array}$ & $\hat{Y}=13,3073+99,3991 X-96,2104 X^{2}$ & 38,98 & 0,516 & 0,170 & 0,92 & 10,783 \\
\hline $\begin{array}{l}\text { Cinza tíbia }(\mathrm{g}) \\
\text { Tibia ash }\end{array}$ & $\hat{Y}=-0,64745+10,9302 X-10,326 X^{2}$ & 2,24 & 0,529 & 0,174 & 0,98 & 2,517 \\
\hline $\begin{array}{l}\text { Fósforo tíbia (\%) } \\
\text { Tibia phosphorus }\end{array}$ & $\hat{Y}=1,54819+19,4415 X-16,9108 X^{2}$ & 7,13 & 0,575 & 0,190 & 0,90 & 0,827 \\
\hline $\begin{array}{l}\text { Fósforo tíbia (g) } \\
\text { Tibia phosphorus }\end{array}$ & $\hat{Y}=-0,12259+1,87227 X-1,64827 X^{2}$ & 0,41 & 0,567 & 0,187 & 0,96 & 28,485 \\
\hline
\end{tabular}

* $(\mathrm{P}<0,05)$ pelo teste $\mathrm{F}$.

1 Estimado pela equação da reta em Newton e resposta máxima em $\mathrm{kgf} / \mathrm{mm}$, em que $1 \mathrm{~N}=0,1020 \mathrm{kgf} / \mathrm{mm}$.

* $(P<.05)$ by $F$ test.

1 Estimated by the regression equation in Newton and maximum answer in $\mathrm{kgf} / \mathrm{mm}$, where $=.1020 \mathrm{kgf} / \mathrm{mm}$. 
Rev. bras. zootec.

Tabela 8 - Exigência de fósforo disponível para frangos de corte machos e fêmeas, de 1 a 21 dias de idade, considerando as variáveis de desempenho estimadas pelo modelo L.R.P

Table 8 - Available phosphorus requirement, for male and female broilers, from 1 to 21 days of age, considering the performance variable estimated by LRP models

\begin{tabular}{|c|c|c|c|c|c|c|}
\hline \multirow{2}{*}{$\begin{array}{l}\text { Variáveis } \\
\text { Variable } \\
\text { Desempenho } \\
\text { Performance }\end{array}$} & \multirow[t]{2}{*}{$\begin{array}{c}\text { Equação da reta } \\
\text { Regression equation }\end{array}$} & \multirow[t]{2}{*}{$\begin{array}{c}\text { Platô } \\
\text { Max. point }\end{array}$} & \multicolumn{2}{|c|}{$\begin{array}{c}\text { Exigências } \\
\text { Requeriments } \\
(\%)(\% / \text { Mcal EM })\end{array}$} & \multirow[t]{2}{*}{$\begin{array}{l}\mathrm{R}^{2 *} \\
S S D\end{array}$} & \multirow[t]{2}{*}{ SQD } \\
\hline & & & & & & \\
\hline \multicolumn{7}{|l|}{ Machos (Male) } \\
\hline $\begin{array}{l}\text { Ganho de peso } \\
\text { Wigth gain }\end{array}$ & $\hat{Y}=-152,7503+2620,0010 X$ & 670,875 & 0,314 & 0,104 & 0,94 & 1793,188 \\
\hline $\begin{array}{l}\text { Conv. alimentar } \\
\text { Feed:gain ratio } \\
\text { Fêmeas } \\
\text { Female }\end{array}$ & $\hat{\mathrm{Y}}=2,7591-4,0668 \mathrm{X}$ & 1,70 & 0,259 & 0,085 & 0,79 & 0,0010 \\
\hline $\begin{array}{l}\text { Ganho de peso } \\
\text { weigth gain }\end{array}$ & $\hat{Y}=-46,7501+2120,00 X$ & 603,500 & 0,307 & 0,101 & 0,94 & 1498,500 \\
\hline $\begin{array}{l}\text { Conv. alimentar } \\
\text { Feed:gain ratio }\end{array}$ & $\hat{\mathrm{Y}}=2,1504-1,0707$ & 1,72 & 0,397 & 0,131 & 0,80 & 0,0001 \\
\hline
\end{tabular}

* $(\mathrm{P}<0,05)$ pelo teste $\mathrm{F}$.

1 Estimado pela equação da reta em Newton e resposta máxima em $\mathrm{kgf} / \mathrm{mm}$, em que $1 \mathrm{~N}=0,1020 \mathrm{kgf} / \mathrm{mm}$.

* $(P<.05)$ by $F$ test.

1 Estimated by the regression equation in Newton and maximum answer in $\mathrm{kgf} / \mathrm{mm}$, where $=.1020 \mathrm{kgf} / \mathrm{mm}$.

Tabela 9 - Exigência de fósforo disponível, para frangos de corte machos e fêmeas, de 1 a 21 dias de idade, considerando as variáveis ósseas, estimadas pelo modelo LRP

Table 9 - Available phosphorus requirement, for male and female broilers, from 1 to 21 days of age, considering the bone variables estimated by LRP models

\begin{tabular}{|c|c|c|c|c|c|c|}
\hline \multirow{2}{*}{$\begin{array}{l}\text { Variáveis } \\
\text { Variable } \\
\text { Ósseas (Bone) } \\
\end{array}$} & \multirow[t]{2}{*}{$\begin{array}{c}\text { Equação da reta } \\
\text { Regression equation }\end{array}$} & \multirow[t]{2}{*}{$\begin{array}{c}\text { Platô } \\
\text { Max. point }\end{array}$} & \multicolumn{2}{|c|}{$\begin{array}{c}\text { Exigências } \\
\text { Requeriments } \\
(\%)(\% / \text { Mcal EM })\end{array}$} & \multirow[t]{2}{*}{$\mathrm{R}^{2 *}$} & \multirow[t]{2}{*}{$\begin{array}{l}\text { SQD } \\
S S D\end{array}$} \\
\hline & & & & & & \\
\hline \multicolumn{7}{|l|}{$\overline{\text { Machos (Male) }}$} \\
\hline $\begin{array}{l}\text { Resist. tíbia }{ }^{1} \\
\text { Tibia strength }\end{array}$ & $\hat{Y}=-83,6024+760,1783 X$ & 23,37 & 0,411 & 0,136 & 0,95 & 8,663 \\
\hline $\begin{array}{l}\text { Cinza tíbia }(\%) \\
\text { Tibia ash }\end{array}$ & $\hat{Y}=13,2769+65,2625 X$ & 37,85 & 0,377 & 0,124 & 0,92 & 1,782 \\
\hline $\begin{array}{l}\text { Cinza tíbia }(\mathrm{g}) \\
\text { Tibia ash }\end{array}$ & $\hat{\mathrm{Y}}=-0,3402+7,5572 \mathrm{X}$ & 2,61 & 0,390 & 0,128 & 0,95 & 0,0233 \\
\hline $\begin{array}{l}\text { Fósforo tíbia }(\mathrm{g}) \\
\text { Tibia phosphorus } \\
\text { Fêmeas (Female) }\end{array}$ & $\hat{\mathrm{Y}}=-0,1049+1,4044 \mathrm{X}$ & 0,46 & 0,401 & 0,132 & 0,94 & 0,0008 \\
\hline $\begin{array}{l}\text { Resist. tíbia }{ }^{1} \\
\text { Tibia strength }\end{array}$ & $\hat{Y}=-63,6407+665,1378 X$ & 19,07 & 0,377 & 0,124 & 0,96 & 3228,130 \\
\hline $\begin{array}{l}\text { Cinza tíbia (\%) } \\
\text { Tibia ash }\end{array}$ & $\hat{\mathrm{Y}}=20,3313+40,5749 \mathrm{X}$ & 38,08 & 0,437 & 0,144 & 0,91 & 1,477 \\
\hline $\begin{array}{l}\text { Cinza tíbia }(\mathrm{g}) \\
\text { Tibia ash }\end{array}$ & $\hat{\mathrm{Y}}=-0,0959+5,8622 \mathrm{X}$ & 2,17 & 0,387 & 0,128 & 0,93 & 0,0116 \\
\hline $\begin{array}{l}\text { Fósforo tíbia(\%) } \\
\text { Tibia phosphorus }\end{array}$ & $\hat{\mathrm{Y}}=1,9646+13,4250 \mathrm{X}$ & 6,93 & 0,370 & 0,122 & 0,93 & 0,518 \\
\hline $\begin{array}{l}\text { Fósforo tíbia }(\mathrm{g}) \\
\text { Tibia phosphorus }\end{array}$ & $\hat{\mathrm{Y}}=-0,0432+1,1027 \mathrm{X}$ & 0,40 & 0,399 & 0,132 & 0,95 & 0,0016 \\
\hline
\end{tabular}

* $(\mathrm{P}<0,05)$ pelo teste $\mathrm{F}$.

1 Y Estimado pela equação da reta em Newton e resposta máxima em $\mathrm{kgf} / \mathrm{mm}$, em que $1 \mathrm{~N}=0,1020 \mathrm{kgf} / \mathrm{mm}$.

* $(P<.05)$ by $F$ test.

1 Estimated by the regression equation in Newton and maximum answer in $\mathrm{kgf} / \mathrm{mm}$, where $=.1020 \mathrm{kgf} / \mathrm{mm}$. 


\section{Conclusões}

Considerando-se as respostas biológicas obtidas pelas aves para as variáveis de desempenho e características ósseas, pode-se sugerir que a exigência de fósforo disponível para frangos de corte machos e fêmeas de 1 a 21 dias de idade é de 0,45 ou $0,148 \%$ de P-disp/Mcal de EM.

\section{Referências Bibliográficas}

ABREU, R.D. Exigência nutricional de fósforo e sua disponibilidade em diversos alimentos para aves. Viçosa, MG: UFV, 1989. 142p. Tese (Doutorado em Zootecnia) - Universidade Federal de Viçosa, 1989.

BELLAVER, C., GUIDONI, A.L., ALBINO, L.F.T. et al. 1987. Fontes e níveis de fosfatos de rocha sobre o desempenho de frangos de corte Pesq. Agropec. Bras., 22(9/10):1085-1091.

BOLLING, S.D., DOUGLAS M. W., WANG, X. et al. 2000. The effects of dietary available phosphorus levels and phythase on performance of young and older laying hens. Poult. Sci., 79(2):224-230.

BRAGA, J.M. 1983. Avaliação de fertilidade do solo (ensaios de campo).Viçosa, MG: UFV. p.101. (Pub.,156).

BRUGALLI, I. Efeito da granulometria na biodisponibilidade de fósforo e nos valores energéticos da farinha de carne e ossos e exigência nutricional de fósforo para pintos de corte. Viçosa, MG: UFV, 1996. 83p. Dissertação (Mestrado em Zootecnia) - Universidade Federal de Viçosa, 1996.

DALE, N. 1983. Necessidades de fósforos para pollos. Avicultura Professional. p.80-83.

DAMRON, B.L, FLUNKER, L.K. 1991. Suplementation of broilers drinking water with liquid ammonium polyphosphate. Brit. Poult. Sci., 32(2):377-382.

GOMES, P.C., GOMES, M.F.M., ALBINO, L.F.T. et al. 1994. Exigência de fósforo disponível para frangos de corte nas fases de crescimento e terminação. R. Soc. Bras. Zootec., 23(4):615-622.

GOMES, P.C., GOMES, M.F.M., LIMA, G.J.M.M. et al. 1993. Exigência de fósforo e sua disponibilidade nos fosfatos monoamônio e monocálcico para frangos de corte até 21 dias de idade. R. Soc. Bras. Zootec., 22(5):755-763.

JUNQUEIRA, O.M., KNOOP, R., SAKOMURA, N.K. 1993. Meat and bone meal and dicalcium phosphate as phosphorus sources in broilers diets. Poult. Sci., 72:123 (Suppl.1).

KOCH, M.E., MAHAN, D.C., CORLEY, J.R. 1984. An evaluation of various biological characteristics in assessing low phosphorus intake in weanling swine. J. Anim. Sci., 59(6):1546-1556.

LESKE, K. L., COON, C. 1999. A bioassay to determine the effect of phytase on phytate phosphorus hydrolysis and total phosphorus retention of feed ingredients as determined with broilers and laying hens. Poult. Sci., 78(8):1151-1157.

LIBAL, G.W., PEO, E.R., ANDREWS, R.P. 1969. Levels of calcium and phosphorus for growing- finishing swine. J. Anim. Sci., 28(1):331-335.

LIMA, F.R., MENDONÇA JR., C.X., ALVAREZ, J.C. et al. 1995. Chemical and physical evaluations of commercial dicalcium phosphates as sources of phosphorus in animal nutrition. Poult. Sci., 74(10):1659-1670.

LIMA, I.L. Disponibilidade de fósforo e de flúor de alguns alimentos e exigência nutricional de fósforo para frangos de corte. Viçosa, MG: UFV, 1995. 121p. Tese (Doutorado em Zootecnia) Universidade Federal de Viçosa, 1995.
MAYNARD, L.A., LOOSLY, J.K., HINTZ, H.F. et al. 1984. Nutrição animal. 3.ed., Rio de Janeiro: Freitas Bastos. 736p.

MORRIS, T.R. 1983. The interpretation of response data from animal feeding trials. Rec. Adv. Anim. Nutr., 6:1-11.

NATIONAL RESEARCH COUNCIL - NRC. 1994. Nutrients requeriments of poultry. 9.ed., Washington, D.C. 155 p.

NELSON, T.S., KIRBY, L.K., JOHNSON, Z.B. 1992. Effects of calcium, phosphorus, and energy on the incidence of weak legs in heavy male broilers. J. Appl. Poult. Res., 1(1):11-18.

PARMER, T.G., CAREW, L.B., ALTER, F.A. 1987. Thyroid function, growth hormone, and organ growth in broiler deficient in phosphorus. Poult. Sci., 66:1995-2004.

ROSTAGNO, H.S., SILVA, D.J., COSTA, P.M.A. et al. 1983. Composição de alimentos e exigências nutricionais de aves e suínos: tabelas brasileiras. 6.ed. Viçosa, MG: UFV. 59p.

ROSTAGNO, H.S., SAKOMURA, N.K., GOMES, P.C. et al. 1988. Exigência nutricional de fósforo e sua disponibilidade em fosfato de rocha e fosfato parcialmente defluorizado para pintos de corte. R. Soc. Bras. Zootec., 17(3):249-257.

ROSTAGNO, H.S., BARBARINO JR., P., BARBOSA,W.A. Exigências nutricionais das aves determinadas no Brasil. In: SIMPÓSIO INTERNACIONAL SOBRE EXIGÊNCIAS NUTRICIONAIS DE AVES E SUÍNOS, 1996, Viçosa, MG. Anais... Viçosa, MG: DZO, 1996. p.361-388.

SHAFEY, T.M., McDONALD, M.W., PYM, R.A. 1990. Effects of dietary calcium, avaliable phosphorus and vitamin $d$ on growth rate, food utilisation, plasma and bone constituents and calcium and phosphorus retention of commercial broiler strains. Br. Poult. Sci., 31(3):587-602.

SHAFEY, T.M., McDONALD M.W., DINGLE J.G. 1991. Effects of dietary calcium and avaliable phosphorus concentration on digesta $\mathrm{ph}$ and on the avaliable of calcium, iron, magnesium and zinc from the intestinal contents of meat chickens. Br. Poult. Sci., 32(1):185-194.

SHAFEY, T.M., McDONALD M.W. 1991. The effects of dietary concentrations of minerals, source of protein, amino acids and antibiotcs on the growth of and digetibility of amino acids by broiler chickens. Br. Poult. Sci., 32:535-544.

SILVA, D.J. 1980. Análise de alimentos (métodos químicos e biológicos). Viçosa: UFV. 160p.

SISSON, D., GROSSMAN, K. 1981. Anatomia dos animais domésticos. Rio de Janeiro: Interamericana, 5.ed. 1134p.

UNIVERSIDADE FEDERAL DE VIÇOSA - UFV. 1982. Central de Processamento de Dados- UFV-CPD. SAEG - Sistema para análise estatística e genética. Viçosa, MG: UFV. 59p.

UNDERWOOD, E.J. 1981. Los minerales em la nutrición del ganado. Zaragoza: Acribia. 210p.

WALDROUP, P.W., WMITCHELL, R.J., JOHNSON, Z.B. 1975. The phosphorus needs of young broiler chicks in relationship to dietary nutrient density level. Poult. Sci., 54:436-441.

Recebido em: $17 / 03 / 00$

Aceito em: 15/09/00 